\title{
EDUCAÇÃO AMBIENTAL: PRÁTICAS AMBIENTAIS UTILIZANDO OS ESPAÇOS PÚBLICOS NA CIDADE DE MANAUS
}

\section{Silvana Heloísa Ferreira Cruz ${ }^{1}$}

\section{RESUMO}

O presente artigo aborda as práticas ambientais construídas a partir dos espaços públicos na cidade de Manaus, analisa as políticas públicas de educação ambiental do município de Manaus, cita exemplos de boas práticas de educação ambiental desenvolvidas pelo poder público, bem como critica a falta de sistematização e continuidade do trabalho de educação ambiental oferecida à população, recomenda algumas metodologias sustentáveis a serem construídas utilizando os espaços públicos para se trabalhar a educação ambiental nas modalidades de ensino formal, não formal e informal. É um estudo descritivo apoiado em documentos oficiais como as Conferências Internacionais, Parâmetros Curriculares Nacionais, Lei de Diretrizes e Bases da Educação Nacional n ${ }^{\circ}$ 9.394/96 e Resolução n 2, de 15 de junho de 2012 que estabelece as Diretrizes e Bases da Educação Ambiental.

PALAVRAS-CHAVE: Educação Ambiental; ensino; metodologias

\section{ENVIRONMENTAL EDUCATION: ENVIRONMENTAL PRACTICES USING PUBLIC IN MANAUS CITY}

\begin{abstract}
This article discusses the environmental practices built from the public spaces in the city of Manaus , analyzes public policies on environmental education in the municipality of Manaus, cites examples of good practice in environmental education developed by the government and criticizes the lack of systematization and continuity of environmental education offered to the population, recommends some sustainable methodologies to be built using public spaces to work for environmental education in terms of formal education, non-formal and informal . It is a descriptive study supported in official documents as the International Conferences, National Curriculum Parameters, Law of Directives and Bases of National

\footnotetext{
${ }^{1}$ Mestra em Educação pela Faculdade de Educação (FACED/UFAM), Pedagoga do Centro de Ciências do Ambiente - Universidade Federal do Amazonas (CCA/UFAM) e Doutoranda em Ciências da Educação - Universidade de Trásos-Montes e Alto Douro (UTAD), Vila Real - Portugal.
} 
Education in 9394 / 96 and Resolution No. 2 of 15 June 2012 laying down Guidelines and Bases of Environmental Education

KEYWORDS: Environmental Education; education; methodologies.

\section{EDUCACIÓN AMBIENTAL: PRÁCTICAS AMBIENTALES QUE UTILIZAN PÚBLICO EN MANAUS CIUDAD}

\section{RESUMEN}

Este artículo analiza las prácticas ambientales construidos a partir de los espacios públicos de la ciudad de Manaus, analiza las políticas públicas de educación ambiental en el municipio de Manaus, cita ejemplos de buenas prácticas en materia de educación ambiental desarrolladas por el gobierno y critica la falta de sistematización y la continuidad de la educación ambiental que ofrece a la población , recomienda algunas metodologías sostenibles que se construirán utilizando el espacio público para trabajar por la educación ambiental en términos de la educación formal, no formal e informal. Se trata de un estudio descriptivo apoyado en documentos oficiales como las Conferencias Internacionales , Parámetros Curriculares Nacionales, Ley de Directrices y Bases de la Educación Nacional en 9394/96 y la Resolución $N^{\circ} 2$ de 15 de junio 2012 se establecen las directrices y Bases de la Educación Ambiental PALABRAS-CLAVE: Educación Ambiental; la educación; metodologías

\section{INTRODUÇÃO}

Na cidade de Manaus, a educação ambiental nos locais públicos é uma prática em construção, em alguns lugares, observa-se a ausência quase que total de políticas públicas de educação ambiental.

Vejamos alguns exemplos de práticas equivocadas executadas pelo poder público no trato com o meio ambiente, no caso em voga é a sujeira nos igarapés realizada pelos moradores da cidade que por falta possivelmente de conhecimento sobre o meio ambiente, acabam descartando seu lixo nos igarapés. Então, para sanar e ou minimizar o problema ambiental, todos os anos a prefeitura através da Secretaria Municipal de Limpeza e Serviços Públicos ( SEMULSP) gasta fortunas em dinheiro na limpeza de igarapés, são retirados toneladas de lixo como: embalagens pets, garrafas 
de refrigerantes e de cervejas, vidros, sacos de plásticos, geladeiras, máquinas de lavar, fogões, sofás, latas de alumínio, camas, colchões, lixo doméstico entre outros que além de causarem prejuízos ao meio ambiente, demoram muito para se decomporem.

Para se ter uma ideia, o quadro degradante ambiental apresentado além de causar consequências negativas ambiental e social, custa muito caro aos cofres públicos, pois, "o mau hábito de jogar lixo e consequentemente poluir os igarapés tem um custo muito alto, nos cinco primeiros meses deste ano a Prefeitura de Manaus gastou mais de $R \$ 4.198$ de milhões com o serviço de limpeza dos igarapés, nesse período foram coletados 3.986 toneladas de lixo" (MESQUITA, 2014).

Diante de tal quadro, observa-se que os moradores que vivem no entorno e nas encostas dos igarapés são oriundas das camadas menos favorecida economicamente, esses, são os mais prejudicadas, principalmente no período da enchente, pois o nível de águas sobe e com ele a sujeira fica bem visível, seus moradores ficam expostos a todo tipo de contaminação, como: doenças provocadas por picadas de insetos, animais peçonhentos, roedores, águas contaminadas entre outras.

A falta de cuidado com o meio ambiente desenhado neste quadro, a poluição nos igarapés feita possivelmente pela grande maioria da população, revela que se faz necessário mais investimentos em políticas de educação ambiental na cidade de Manaus.

Sabe-se que para melhorar a qualidade de vida dos moradores, são necessários grandes investimentos por parte do poder público em várias áreas como: em saneamento básico, saúde, educação, segurança, esporte, cultura, lazer entre outras.

Pretende-se neste artigo, enfatizar a aplicação da educação ambiental nas modalidades de ensino formal, não formal e informal, explicar que esta, pode ser uma grande aliada na soluções dos problemas ambientais ora apresentados, até porque, a prática pedagógica do ensino de educação ambiental aplicada nos diversos ambientes, 
configura-se em uma possibilidade na construção de um ambiente ecologicamente equilibrado, atenuando os problemas ambientais tão prejudiciais à saúde das diversas formas de vida.

A educação ambiental surge como uma prática educativa transformadora no sentido de abordar questões relacionadas aos problemas ambientais e incutir no homem a sua responsabilidade para o cuidado e a ética que ele deve ter com o ambiente e com todas as formas de vida, objetiva refletir sobre os reflexos negativos causados pelo sistema econômico capitalista na natureza, bem como buscar alternativas sustentáveis para a melhoria de vida no planeta, neste sentido busca-se compreender na cadeia alimentar, o homem e sua inter-relação com os seres vivos e seu compromisso na preservação e conservação ambiental.

Também compete a educação ambiental dentre outras possibilidades a de promover no indivíduo e na coletividade, mudança de postura, hábitos, atitudes e valores para com o meio ambiente.

A escola tem um papel preponderante na difusão e construção de saberes ambientais à sociedade, assim sendo, é necessário que o professor inicie seu trabalho com temas ambientais oriundos do contexto socioambiental de seu aluno, promovendo questionamentos e soluções para as questões apresentadas.

No ensino formal, a escola pode trabalhar a educação ambiental, segundo REIGOTA (2009:46):

A educação ambiental escolar deve-se enfatizar o estudo do meio ambiente onde vive 0 aluno e a aluna, procurando levantar os principais problemas cotidianos, as contribuições da ciência, da arte, dos saberes populares, enfim, os conhecimentos necessários e as possibilidades concretas para a solução deles.

Nos espaços não formal e informal, a educação ambiental pode ser desenvolvida em ambientes diversificados como: praças, portos, aeroportos, templos religiosos, mercados, feiras, shoppings, jardins, museus, teatros, zoológicos, pontes, viadutos, largos, parques ecológicos, reservas ecológicas, ruas, igarapés e áreas 
degradas com aplicação de projetos de recuperação de áreas verdes degradadas, entre outros.

Ressalta-se que para cada um desses locais, há inúmeras possibilidades de se desenvolver um trabalho de cunho ambiental, como caminhadas ecológicas, exposição de quadros de pintura, varal ecológico, músicas ecológicas, peças teatrais, filmes ecológicos, jogos educativos, dominós com a fauna e flora amazônica, faixas ecológicas, shows musicais, entrevistas em rádios e na televisão, palestras e encontros com especialistas da área dentre outros.

Há de se considerar que a educação ambiental deve ser trabalhada de forma transversal, no tema meio ambiente, utilizando a metodologia interdisciplinar, pois a interdisciplinaridade possibilita um diálogo com as diversas áreas do conhecimento, isto implica uma compreensão ampla do conhecimento, tais recomendações foram dadas pelos Parâmetros Curriculares Nacionais (PCN).

A construção de conhecimentos trabalhada de forma interdisciplinar com temáticas regionais e universais, possibilita mudanças de postura, hábitos e atitudes do indivíduo para com o meio ambiente, nesse sentido, os órgãos ambientais junto com outras entidades, poderão inicialmente desenvolver um trabalho pedagógico, sistemático e contínuo, de cunho ambiental no sentido de possibilitar a construção de uma consciência ambiental aos moradores, bem como, sensibilizar, despertar a população para os problemas ambientais, neste sentido faz-se necessário, convidar as pessoas para o debate, um tema inicial poderia ser: a produção e o descarte dos resíduos sólidos, informando ao morador de seu papel e de sua responsabilidade para o cuidado que todos devem ter com seu meio ambiente.

O tema: Educação Ambiental: Práticas Ambientais Construídas Utilizando os Espaços Públicos na Cidade de Manaus, tem como objetivo analisar as políticas de educação ambiental desenvolvidas e aplicadas nos espaços públicos da cidade de Manaus nas modalidades de ensino formal, não formal e informal, bem como apontar algumas metodologias educativas para o desenvolvimento e aplicação da educação ambiental a partir de tais espaços. 


\section{ALGUMAS CONSIDERAÇÕES ACERCA DA EDUCAÇÃO AMBIENTAL NOS DOCUMENTOS OFICIAIS}

Com base no referencial histórico-teórico, a educação ambiental parece configurar-se em um novo paradigma de conhecimento, uma vez que a fragmentação do saber apresentada no modelo cartesiano de ensino, reduz e limita o saber. A educação ambiental intenta melhorar a relação homem, natureza e sociedade, sendo que o homem aparece não como o grande vilão, mas como o sujeito inter-relacionado na cadeia alimentar. Surge também, da necessidade de solucionar os problemas ambientais causados pelo modelo de desenvolvimento econômico capitalista de caráter exploratório e predatório uma vez que utiliza cada vez mais os recursos naturais para garantir o funcionamento desse sistema, a exploração dos recursos renováveis e não renováveis de forma não sustentável, pode levar o esgotamento de tais recursos a uma situação insustentável.

Afim de evitar uma análise exaustiva, podemos dizer historicamente que a Educação Ambiental está presente nas conferências e encontros internacionais: Estocolmo, 1972; Tbilisi,1977; Belgrado, 1985; Moscou, 1987; Rio,1992; Rio + 10, Joanesburgo, 2002. Os referidos documentos propõem a educação ambiental como políticas públicas de estado.

Podemos dizer que todos esses encontros e conferências foram de grande importância para a difusão e consolidação da Educação Ambiental em níveis internacional e nacional, bem como os documentos produzidos pelos referidos encontros servem de referências para a educação ambiental. É possível dizer que passados mais de quatro décadas do surgimento da educação ambiental em nível planetário, no Brasil a educação ambiental está em construção, ainda há muito a ser feito para a efetivação da prática de educação ambiental, especificamente no âmbito local. 
É possível dizer que para se ter uma boa difusão e aplicação do ensino da educação ambiental nas modalidades de ensino formal, não formal e informal, são necessários grandes investimentos para formação de professores e profissionais ambientais, isto implica estímulo à formação inicial e continuada desses profissionais, bem como intensificação em campanhas educativas através dos meios de comunicação, fiscalização e punição aos poluidores do meio ambiente.

Para ilustrar o nosso artigo, serão apresentados alguns princípios de Educação Ambiental de Tbilisi, 1977 de acordo os PCN:

. considerar o meio ambiente em sua totalidade: em seus aspectos natural e construído, tecnológicos e sociais ( econômico, político, histórico, cultural, técnico, moral e estético);

. constituir um processo permanente e contínuo durante todas as fases do ensino formal;

- aplicar um enfoque interdisciplinar, aproveitando o conteúdo específico de cada área, de modo que se consiga uma perspectiva global da questão ambiental;

. examinar as principais questões ambientais do ponto de vista local, regional, nacional e internacional;

. concentrar-se nas questões ambientais atuais e naquelas que podem surgir, levando em conta uma perspectiva histórica;

- insistir no valor e na necessidade da cooperação local, nacional e internacional para prevenir os problemas ambientais;

- considerar de maneira explícita os problemas ambientais nos planos de desenvolvimento e crescimento;

- promover a participação dos alunos na organização de suas experiências de aprendizagem, dando-lhes a oportunidade de tomar decisões e aceitar suas consequências;

- estabelecer, para os alunos de todas as idades, uma relação entre a sensibilização ao meio ambiente, a aquisição de conhecimentos, a atitude para resolver os problemas e a clarificação de valores, procurando, principalmente, sensibilizar os mais jovens para os problemas ambientais existentes na sua própria comunidade;

- ajudar os alunos a descobrir os sintomas e as causas reais dos problemas ambientais ( tanto as locais quanto as mais amplas, de acordo com as possibilidades de compreensão em cada fase ou ciclo do ensino);

. ressaltar a complexidade dos problemas ambientais e, em consequência, a necessidade de desenvolver o sentido crítico e as atitudes necessárias para resolvê-los;

. utilizar diversos ambientes com a finalidade educativa e uma ampla gama de métodos para transmitir e adquirir conhecimento sobre o meio ambiente, ressaltando principalmente as atividades práticas e as experiências pessoais ( 1998:231/232). 
Esses princípios ambientais devem ser conhecidos, debatidos, socializados com toda a comunidade, para que se possibilite a construção de uma consciência ambiental, bem como a formação da cidadania, isto pode ser feito entre professores, especialistas ambientais e a comunidade em geral.

Outro documento importante oficial referente à educação ambiental, é a Resolução N 2, de 15 de Junho de 2012 que estabelece as Diretrizes Curriculares para a Educação Ambiental, a referida resolução consagra a Educação Ambiental em seu Art. 14 assim assegura:

A Educação Ambiental nas instituições do ensino, com base nos referenciais apresentados, deve contemplar, dos cincos incisos, faremos destaque apenas aos I e II que asseguram:

I - abordagem curricular que enfatize a natureza como fonte de vida e relacione a dimensão ambiental à justiça social, aos direitos humanos, à saúde, ao trabalho, ao consumo, à pluralidade étnica, racial, de gênero, de diversidade sexual, e à superação do racismo e de todas as formas de discriminação e injustiça social;

II - abordagem curricular integrada e transversal, contínua e permanente em todas as áreas de conhecimentos, componentes curriculares e atividades escolares e acadêmicas.

A prática de educação ambiental aplicada nos diversos espaços públicos nas modalidades de ensino formal, não formal e informal, deve estar em harmonia com os preceitos legais, bem como do compromisso e da vontade política dos responsáveis pela socialização dos saberes educativos ambientais, pois as mudanças só poderão ocorrer através do conhecimento e da vontade de mudar, como bem pontua ( Freire, 2011: 75) "No mundo da história, da cultura, da política, constato não para me adaptar, mas para mudar".

\section{EXEMPLOS DE METODOLOGIAS EDUCATIVAS SUSTENTÁVEIS QUE PODEM SER APLICADAS NA CIDADE DE MANAUS UTILIZANDO OS ESPAÇOS PÚBLICOS}


A cidade de Manaus-AM, possui um valioso tesouro histórico-cultural, no centro há prédios que foram construídos no período áureo da borracha, época de um grande ciclo econômico, sendo a seringueira, a árvore da prosperidade, pois desta magnífica árvore se extrai o látex que produz a borracha, tais prédios possuem arquitetura neoclássica retratam a riqueza e opulência da época.

Além dos prédios, a cidade conta com valiosos espaços públicos como: praças, porto, áreas de preservação ambiental, praias entre outros que são perfeitamente adequados para se trabalhar a educação ambiental.

Nas praças podem ser desenvolvidas atividades como: peças teatrais, dramatização, debates, encontros, palestras, atividades de educação física, concurso de música e coreografia.

Pode-se trabalhar a música e ou toadas dos bois-bumbás de Parintins, pois elas apresentam em suas letras: a miscigenação da população, o branco, negro e o índio, os elementos da natureza, os mitos e lendas amazônicas, se constituem verdadeiros hinos ecológicos que denunciam as agressões à natureza e conclamam e defendem todas as formas de vida.

Para ilustrar e reforçar o apelo ecológico presente na música regional, apresentamos um pequeno fragmento da toada Lamento de Raça, autoria de Emerson Maia, do boi bumbá Garantido, assim apresenta:

"O índio chorou/ o branco chorou/ todo mundo ta chorando/ Amazônia está queimando, ai, ai que dor/ ai, ai que horror./ O meu pé de sapopema/ minha infância virou lenha/ ai, ai que dor/ ai, ai que horror/ lá se vai a saracura correndo dessa quentura e não vai mais voltar/ lá se vai onça pintada fugindo dessa queimada e não vai voltar/ lá se vai a macacada junto com a passarada pra nunca mais voltar/ pra nunca mais, nunca mais voltar/ virou deserto o meu torrão/ meu rio secou/ pra onde voooooooou".

A letra denuncia a agonia e a morte dos animais por conta das queimadas na floresta amazônica, assim sendo se continuarem com essas agressões à natureza, todos sofrerão, principalmente o próprio homem, pois sua vida ficará insuportável sem a floresta e seus elementos. 
A prática de educação ambiental precisa adotar a pedagogia do amor com todos os seres, pois esta exigirá, segundo Sardi, 2012:

\begin{abstract}
" [...] mais do que informações sobre espécies, ciclos e processos vitais, a vivência da natureza. Conhecer para amar e amar para conhecer: eis o círculo do sentido humano do conhecimento. De um conhecimento que é prazer, pois confere valor àquilo que assim reconheceu como significativo. Educação do olhar, do sentir, do escutar, do sensibilizar-se, que não mais domina, mas integra-se. Educação da razão, que não apenas explica, mas se põe a serviço da tarefa de constantemente reaprender a amar. Educação do desejo, que não possui, mas oferece. Educação interior e ambiental que principia por aprender a ver a vida com carinho e se consolida em uma ética do cuidado.
\end{abstract}

Um outro exemplo para se trabalhar a educação ambiental é o plantio de mudas em área degradada, esta atividade tem o propósito de recuperar a área degradada provocada pela ação não racional do homem.

Registra-se a realização de uma bom exemplo de políticas públicas voltadas para a plantação de mudas em Manaus, esta tarefa foi realizada recentemente pela Secretaria Municipal de Meio Ambiente e Sustentabilidade (SEMMAS), e instituições parceiras, o plantio de 530 mudas de espécies arbóreas na área de preservação permanente do igarapé do 40. A ação teve como objetivo chamar atenção da sociedade para a importância do verde na melhoria da qualidade ambiental da cidade ( A CRÍTICA, 2014).

\title{
CONSIDERAÇÕES FINAIS
}

Discorrer sobre a Educação Ambiental é muito complexo, devido a sua amplitude, porém é um tema muito apaixonante, envolvente, quando se inicia, não se quer mais parar, até porque tudo está ligado a tudo, assim como é a natureza, manifestada na interdependência dos seres vivos, o que acontece de negativo com um ser vivo, afeta o outro ser, esta é a lógica da existência das espécies.

A ética do cuidado, preconizada por Leonardo Boff (2003), talvez seja uma das saídas para se garantir a continuidade das espécies, o referido autor assim assinala: 
O cuidado é tão essencial que, se bem observarmos, tudo o que fazemos vem acompanhado de cuidado ou de falta de cuidado. Se fazemos com cuidado, tudo pode dar certo e dura mais. Tudo que amamos também cuidamos. A ética do cuidado hoje é tão fundamental: se não cuidarmos do planeta Terra, ele poderá sofrer um colapso e destruir as condições que permitem o projeto planetário humano. A própria política é o cuidado para com o bem do povo.

Faço um convite a todos, vamos cuidar de nosso planeta já, sejamos os verdadeiros guardiões do Planeta Terra. Adotemos a ética do cuidado!

\section{REFERÊNCIAS}

ARQUIDEOCESE DE MANAUS. O canto da Amazônia: vida e missão deste pão. Campanha da Fraternidade 2007, Fraternidade e Amazônia. Manaus,2007.

BOFF, Leonardo. Ética e eco-espiritualidade. Campinas,SP: Verus Editora,2003.

BRASIL. Secretaria de Educação Especial. Parâmetros curriculares nacionais: terceiro e quarto ciclos: apresentação dos temas transversais. Secretaria de Ensino Fundamental. Brasília: MEC/SEF,1998.

FREIRE, Paulo. Pedagogia da autonomia: saberes necessários à pratica educativa. São Paulo, Paz e Terra,2011.

JORNAL A CRÍTICA N 22.817, C 2 Cidades. Manaus, 27 de setembro de 2014.

MESQUITA, Florêncio. Mau hábito que custa 4 mi. Jornal A Critíca N 22.771. Manaus,12 de agosto,2014.

MINISTÉRIO DA EDUCAÇÃO. Resolução $\mathbf{n}^{\circ}$ 2, de 15 de junho de 2012. Diário Oficial da União, Brasília, 18 de junho de 2012 - Seção I - p.70.

REIGOTA, Marcos. O que é educação ambiental. 2. ed. Revista e ampliada. São Paulo: Brasiliense,2009.

SARDI, Sérgio A. A pedagogia do amor com todos os seres. Jornal Mundo Jovem, Porto Alegre, março de 2012.JORNAL MUNDO JOVEM, Porto Alegre, março de 2012. 